\title{
Adaptive feedback and student behaviour in computer-assisted instruction
}

Peter Roels, ${ }^{1,2}$, Griet van Roosmalen, ${ }^{2,3,4}$ \& Carolien van Soom, ${ }^{1,2}$

OBJECTIVES Two packages of adaptive computer-assisted instruction (CAIs), both offering questions and subsequent feedback, were compared in terms of amount of feedback offered, learning efficiency and appreciation. Feedback was either barely more than knowledge of result ('minimal') or consisted of a complete additional learning path ('elaborate'). The CAIs differed in the way the type of feedback given was triggered.

METHODS A total of 97 Bachelor of Science students were stratified based on a pre-test before the experiment and were allocated randomly to two groups to receive either a 'programme-assessed' or a 'student-assessed' treatment. In the former, the feedback provided by the CAI (either elaborate or minimal) was completely determined by the objective correctness of the student's response. In the student-assessed treatment, elaborate feedback was provided only to students who stated explicitly that they did not know the answer. Afterwards, students completed a post-test and an appreciation questionnaire.

RESULTS Both CAIs resulted in a significant learning effect, but overall the effect was sig- nificantly higher in the programme-assessed treatment. Students using the student-assessed CAI hardly ever used the 'I don't know' option and therefore received mostly minimal feedback. There was no difference in students' appreciation between treatments. An interaction between the learner's prior knowledge and treatment was found: for learners with a high level of prior knowledge the programme-assessed treatment resulted in significantly higher learning effectiveness compared with the student-assessed treatment, whereas for learners with a low level of prior knowledge there was no significant difference.

CONCLUSIONS Our results demonstrate that learners achieved a significantly higher learning effectiveness in the programmeassessed treatment in which the received feedback was fully controlled by the correctness of the answer, compared with the student-assessed treatment. In the latter, students hardly ever admitted to not knowing the answer. Therefore, student-initiated use of the tool in a student-assessed CAI requires to be improved.

\footnotetext{
${ }^{1}$ Tutorial Services, Faculty of Science, Catholic University of Leuven, Leuven, Belgium

${ }^{2}$ Leuven Engineering Science Education Centre, Associated with the Catholic University of Leuven, Leuven, Belgium

${ }^{3}$ Department of Educational Sciences, Centre for Research on Teaching and Training, Catholic University of Leuven, Leuven, Belgium
}

\footnotetext{
${ }^{4}$ Department of Industrial Biosciences, Katholieke Hogeschool Kempen, Geel, Belgium

Correspondence: Peter Roels, K.U. Leuven, Monitoraat Wetenschappen, Celestijnenlaan 200i, 3001 Heverlee, Belgium. Tel: 00321632 7116; Fax: 00321632 7997;

E-mail: peter.roels@wet.kuleuven.be
} 


\section{INTRODUCTION}

Mitosis and meiosis are important, yet conceptually difficult, cellular processes. ${ }^{1,2}$ Deep knowledge of this subject is essential to the full understanding of Mendelian genetics and genetic variation. New students in Bachelor of Science programmes have at least some factual knowledge deriving from their secondary school education. However, the level of prior knowledge differs substantially among students, many of whom have a very limited conceptual understanding. ${ }^{3}$ In order to improve the conceptual learning of mitosis and meiosis by bachelor students, we developed a package of adaptive computerassisted instruction (CAI) and compared its learning effect with that of a traditional lecture. ${ }^{3}$ Because we observed that learning effectiveness was rather small in both the CAI and the traditional lecture, the main goal of the current study was to optimise the effectiveness of the CAI.

Learners' prior knowledge is generally considered to be one of the most important student-specific factors affecting study performance. ${ }^{4,5}$ Efficient learning requires the level of task difficulty to be adapted to the knowledge base of the learner. ${ }^{6-10}$ In addition, students should be able to recognise the opportunity to learn as such, should have the ability to grasp and make use of this opportunity, and should be motivated to do so effectively. ${ }^{11,12}$

In computer-based learning, such as adaptive hypermedia or CAI, it is possible to offer individualised learning paths through the subject matter based on an assessment of the learner's prior knowledge. An adaptive CAI enables the detection and remediation of specific misconceptions and supplies feedback adapted to each learner's needs. Adaptive CAIs have been proposed to improve learning effectiveness and efficiency, ${ }^{8,13}$ both for learners with low levels of prior knowledge (by avoiding 'cognitive overload'7,14) and for learners with high levels of prior knowledge (by avoiding an 'expertise reversal effect ${ }^{\text {,7 }}$ ). The additional learning paths provided during CAI can be invoked either by the student or by the system. Student-invoked learning paths are more generally referred to in the literature as 'tools' of which the use depends on the learner's initiative. System-invoked learning paths are fully integrated in the learning environment and confront learners with learning paths without requiring them to request them. Although learner control is generally supposed to establish a 'better' learning environment as a result of the appeal it makes to the autonomy of the learner, a clear benefit of learner control on learning has not been found (reviewed in ${ }^{15-18}$ ). Several studies report that students tend to avoid using available tools, and that effective tool use depends on learner, tool and task characteristics (reviewed in ${ }^{19}$ ). In addition, no clear indication has been found for a learning effect of tool use. ${ }^{19}$

We designed two different adaptive CAIs based on the same set of learning goals that emphasise conceptual knowledge of the subject. The CAIs offered identical types of feedback and differed only in the way feedback was triggered. In one CAI, a programme-assessed treatment, the type of feedback provided was completely determined by the objective correctness of the student's response to the question: a wrong answer triggered a learning path with a theoretical argument and/or additional questions (hereafter called 'elaborate feedback'), whereas a correct answer resulted in barely more than knowledge of the result (hereafter called 'minimal feedback'). In the other CAI, a studentassessed treatment, students could receive the elaborate feedback only by explicitly stating that they did not know the answer to the question. Giving students the opportunity to read elaborate feedback prior to answering a question allowed them to potentially access a higher number of successful experiences.

This study addressed the following research questions:

1 Do both adaptive CAIs result in a learning effect?

2 Do students in the student-assessed treatment receive a comparable amount of elaborate feedback relative to the programme-assessed treatment? If so, is learning effectiveness and student appreciation in the former treatment higher than in the latter?

3 How is the amount of received feedback related to both treatment and prior knowledge?

We hypothesised that both adaptive CAIs would result in a significant learning effect, but that overall the student-assessed treatment would result in higher learning effectiveness and higher levels of student appreciation. Indeed, as a learner's willingness to learn is a crucial factor in the learning process, ${ }^{20,21}$ students who explicitly stated that they did not know the answer were expected to be more willing to mentally invest in subsequent learning activities, resulting in higher levels of learning effectiveness and appreciation. By contrast, as students with low levels of prior knowledge are at risk of making mistakes 
without realising it, ${ }^{22}$ we suspected that low prior knowledge users might benefit more from a programme-assessed CAI with fully embedded support and feedback; specifically, in the latter students, the student-assessed treatment might result in a reduced amount of elaborate feedback (and, as a consequence, learning effectiveness) compared with the programme-assessed treatment.

\section{METHODS}

\section{Participants}

Participants included 97 bachelor students in the Faculty of Science at the Catholic University of Leuven (Katholieke Universiteit Leuven [KU Leuven], Leuven, Belgium), who attended the genetics class on the day of the experiment.

National practice in Belgium does not require the provision of informed consent for educational studies and surveys. Participants cannot be identified from the material presented. Students were stratified based on a pre-test taken 1 week before the experiment, and subsequently allocated randomly to two groups which received either the programme-assessed or student-assessed treatment. Data were discarded (listwise deletion) for 15 students who did not take the pre-test, for two students who did not complete the experiment and for one student who had an extreme score (i.e. more than three box-lengths from the edge of the box in the boxplot on the main dependent variable based on the comparison of the mean and the 5\% trimmed mean ${ }^{23}$ ). Details of the remaining students are shown in Table 1.

\section{Intervention and tools used}

One week before the experiment and without prior warning, students in a genetics class completed a paper-based pre-test to assess their prior knowledge of mitosis and meiosis.

On the day of the experiment and again without prior warning, students were allocated to either the programme-assessed or student-assessed treatments. After 60 minutes (i.e. more than enough time to finish the entire CAI), all students were asked to complete a paper-based post-test and an appreciation questionnaire. The pre- and post-tests contained the same 10 multiple-choice questions (MCQs). Note that students did not receive any feedback on their answers on the pre-test and that the pre- and posttests were administered 1 week apart.
Table 1 Background characteristics of the research groups

\begin{tabular}{|c|c|c|c|}
\hline & $\begin{array}{l}\text { Programme- } \\
\text { assessed }\end{array}$ & $\begin{array}{l}\text { Student- } \\
\text { assessed }\end{array}$ & $\begin{array}{l}\text { Total } \\
\text { group }\end{array}$ \\
\hline & $n=41$ & $n=38$ & $n=79$ \\
\hline \multicolumn{4}{|l|}{ Age, years } \\
\hline Mean & 18.8 & 18.6 & 18.7 \\
\hline SD & 1.5 & 1.2 & 1.4 \\
\hline \multicolumn{4}{|l|}{ Gender } \\
\hline Male & 17 & 15 & 32 \\
\hline Female & 24 & 23 & 47 \\
\hline \multicolumn{4}{|l|}{ Programme of study } \\
\hline Biology & 17 & 16 & 33 \\
\hline $\begin{array}{l}\text { Biochemistry } \\
\text { and biotechnology }\end{array}$ & 16 & 18 & 34 \\
\hline Other & 8 & 4 & 12 \\
\hline \multicolumn{4}{|c|}{$\begin{array}{l}\text { SD }=\text { standard deviation } \\
\text { The two groups did not differ significantly in age }(t=-0.7 \\
p=0.5) \text {, gender }\left(\chi^{2}=0.03, p=0.9\right) \text { or programme of study } \\
\left(\chi^{2}=1.9, p=0.8\right) \text {. Statistical analysis was performed using } \\
\text { SPSS Version } 16.0 \text { (SPSS, Inc., Chicago, IL, USA). }\end{array}$} \\
\hline
\end{tabular}

The CAIs presented 11 questions covering different topics from a practical point of view, including: the impact of DNA replication and fertilisation on DNA quantity; the chromosome number of a (haploid or diploid) nucleus; structure and genetic content of chromosomes (sister chromatids versus homologous chromosomes, and genes versus alleles), and the specific behaviour of chromosomes and their sister chromatids during the distinct phases of mitosis and meiosis (e.g. segregation and crossing over). The order in which the questions appeared in the CAI allowed the students to use knowledge acquired in previous questions to answer subsequent questions. For eight of the 11 questions, two different types of feedback were provided according to the answer given by the student.

1 Elaborate feedback was given after the student had answered wrongly (programme-assessed treatment) or after the student had selected the 'I don't know' option (student-assessed treatment). Students were presented with a theoretical argument and/or several consecutive questions covering a similar problem 
formulated in a more generalised way. Afterwards, the original question was re-presented, followed by immediate answer-specific feedback and a theoretical explanation as well as the right answer.

2 Minimal feedback was given after a correct answer (programme-assessed treatment) or simply after the student had answered the question (studentassessed treatment). Students received a very short theoretical explanation as well as the correct answer.

In the remaining three questions, feedback was identical in all circumstances.

Thus, the difference between both adaptive CAIs was the criterion used to choose between elaborate and minimal feedback. In the programme-assessed treatment, both elaborate and minimal feedback were evoked by a wrong versus right answer. In the studentassessed treatment, students could trigger elaborate feedback by choosing the 'I don't know' option, but otherwise would receive minimal feedback irrespective of the correctness of their answer. The students in the student-assessed treatment group were explicitly told at the beginning of the CAI that they would be guided through the learning material in the optimal way if they used the 'I don't know' option appropriately.

The CAIs were programmed with Questionmark Perception 3.4 (Questionmark Computing Ltd, London, UK).

The pre- and post-tests were specifically designed for our research because no standard tests on this topic are available. Before they were used, the questions in the test were evaluated by three biology experts and a small test group of students. This qualitative evaluation showed that the questions did indeed distinguish students based on their level of knowledge of mitosis and meiosis. The test-retest reliability was 0.9 $(\mathrm{p}<0.001)$.

The answer options for the MCQs in the pre- and post-tests were based on misconceptions. To resolve the questions, students needed to have an integrated knowledge of the different topics they learned about. An example is shown below.

Two gametes unite to form a zygote. In one chromosome of one of the gametes, a mutated gene is present. The nucleus of the zygote is divided into two through mitosis. How many of the two daughter nuclei possess the mutated gene?
None

1

$\bigcirc 2$

Not answerable

Reasoning:

1 Before mitosis, the DNA replicates, doubling the mutated gene.

2 After mitosis, the two sister chromatids, each containing a mutated gene, are present in both daughter nuclei.

Scores were corrected for gambling by subtracting $1 /(n-1)$ of the score for each wrong answer $(n=$ the number of answer options in the question).

An 11-item questionnaire was developed to measure students' appreciation of the instruction method. Each item (e.g. 'I would have preferred a lecture instead of CAI' or 'During the instruction, I was challenged to think actively about the subject') was evaluated on a 6 -point scale ranging from $1=$ totally disagree to $6=$ totally agree and a mean score was calculated. This questionnaire turned out to be internally consistent (Cronbach's $\alpha=0.70$ ).

RESULTS

\section{Learning effect}

A comparison of pre- and post-test scores indicated a learning effect. A paired-samples $t$-test revealed a significant learning effect for the total group as well as for either the programme-assessed or studentassessed treatment (Table 2). Table 2 also shows Cohen's $d$, based on the original standard deviations (SDs). These effect sizes were all rather large to large.

To control for the ceiling effect on post- minus pre-test scores, a variable hereafter called 'learning effectiveness' was computed by dividing the difference between post- and pre-test scores by the maximum possible gain ( $100 \%$ minus pre-test score) for each student. ${ }^{24}$ In a one-sample $t$-test, this indicator was significantly different from zero in all cases (Table 2), confirming the results of the comparison of raw pre- and post-test scores. Learning effectiveness was used as the main indicator of the learning effect of a CAI. 
Table 2 Test scores and learning effect of computer-assisted instruction packages

\begin{tabular}{|c|c|c|c|c|c|c|c|c|c|}
\hline & \multicolumn{2}{|c|}{ Pre-test, \% } & \multicolumn{2}{|c|}{ Post-test, \% } & \multirow[b]{2}{*}{$t^{*}$} & \multirow[b]{2}{*}{ Cohen's $d$} & \multicolumn{2}{|c|}{$\begin{array}{l}\text { Learning } \\
\text { effectiveness }\end{array}$} & \multirow[b]{2}{*}{$t^{\dagger}$} \\
\hline & Mean & SD & Mean & SD & & & Mean & SD & \\
\hline Total group & 37.6 & 18.2 & 54.8 & 23.0 & $-6.5^{*}$ & -0.8 & 28.2 & 38.6 & $6.5^{+}$ \\
\hline Programme-assessed & 36.6 & 19.0 & 57.0 & 23.5 & -6.2 & -1.0 & 36.5 & 33.5 & $7.0^{+}$ \\
\hline Student-assessed & 38.5 & 17.5 & 52.2 & 22.4 & $-3.3^{\S}$ & -0.7 & 19.4 & 42.1 & $2.8^{\S}$ \\
\hline \multicolumn{10}{|c|}{$\begin{array}{l}\text { * Paired-samples } t \text {-test } \\
\dagger \text { One-sample } t \text {-test } \\
{ }_{p}<0.001 ;{ }^{\S} p<0.01 \\
\text { SD = standard deviation }\end{array}$} \\
\hline
\end{tabular}

Table 3 Comparison of learning effectiveness, received elaborate feedback and student appreciation in the programme-assessed versus student-assessed treatments

\begin{tabular}{|c|c|c|c|c|c|c|}
\hline & \multicolumn{2}{|c|}{ Programme-assessed } & \multicolumn{2}{|c|}{ Student-assessed } & \multirow[b]{2}{*}{$t$} & \multirow[b]{2}{*}{ Cohen's $d$} \\
\hline & Mean & SD & Mean & SD & & \\
\hline Learning effectiveness & 36.5 & 33.5 & 19.4 & 42.1 & $2.0 *$ & 0.5 \\
\hline Elaborate feedback ${ }^{*}$ & 3.8 & 1.4 & 0.6 & 0.9 & $12.0^{\dagger}$ & 2.7 \\
\hline Student appreciation & 4.8 & 0.5 & 4.7 & 0.4 & 1.3 & 0.3 \\
\hline \multicolumn{7}{|c|}{$\begin{array}{l}* p<0.05 ;{ }^{\dagger} p<0.001 \\
\ddagger \text { The number of times that a student received elaborate feedback ranges from } 0 \text { to } 8 \\
\text { SD }=\text { standard deviation }\end{array}$} \\
\hline
\end{tabular}

\section{Programme-assessed versus student-assessed treatments}

Students on the programme-assessed treatment received significantly more elaborate feedback through the learning process. Therefore, we decided to include elaborate feedback as a covariate in the analysis of variance (ANOVA).

A comparison of the learning effectiveness of the programme-assessed treatment with that of the student-assessed treatment (Table 3) showed that pre-test scores did not differ significantly between the groups $(t=0.5, \mathrm{p}=0.7)$, which suggests that students in both groups had similar levels of baseline knowledge of mitosis and meiosis. Subjects receiving the programme-assessed treatment achieved a higher level of learning effectiveness than those receiving the student-assessed treatment (Table 3), although the effect size was rather small.

There was no significant difference between treatments in terms of subjective appreciation.

\section{Low versus high prior knowledge learners}

The use of a tertile split (extreme group analysis ${ }^{25}$ ) enabled the comparison of students with relatively low and relatively high pre-test scores.

To investigate a possible interaction between treatment and prior knowledge, an ANOVA with treatment and pre-test scores as independent variables and elaborate feedback as a dependent variable was computed. In this analysis, main effects of treatment $\left(F_{1,5}=96.0, \mathrm{p}<0.001, \eta_{p}^{2}=2.8\right)$ and prior 
knowledge $\left(F_{1,5}=6.1, \mathrm{p}<0.05, \eta_{p}{ }^{2}=0.5\right)$, but no interaction effect, were found (Table 4). Both low and high prior knowledge learners received more feedback in the programme-assessed condition than in the student-assessed condition. Students with a low pre-test score received more feedback in both the programme- and student-assessed treatments relative to those with a high pre-test score.

An analysis of covariance (ANCOVA) with learning effectiveness as a dependent variable and elaborate feedback as a covariate confirmed the main effect of treatment $\left(F_{1,5}=11.7, \mathrm{p} \leq 0.001, \eta_{p}{ }^{2}=0.2\right)$. Prior knowledge $\left(F_{1,5}=5.9, \mathrm{p} \leq 0.05, \eta_{p}^{2}=0.1\right)$ also had a significant effect on learning effectiveness. High prior knowledge students gained less $($ mean $=20.0$, $\mathrm{SD}=50.7)$ than low prior knowledge students $($ mean $=33.2, \mathrm{SD}=25.9)$. There was also a significant interaction between both independents $\left(F_{1,5}=4.03, \mathrm{p} \leq 0.05\right)$ (Table 4$)$. The programmeassessed treatment was confirmed as more beneficial for high prior knowledge learners, whereas for low prior knowledge learners both treatments were equally beneficial.

An analogous ANCOVA with subjective appreciation of the learning method as a dependent variable found only a significant main effect of elaborate feedback $\left(F_{1,5}=6.1, \mathrm{p} \leq 0.05\right)$. Indeed, a positive correlation existed between amount of elaborate feedback and appreciation of the CAI $(r=0.2, \mathrm{p} \leq 0.05)$.

\section{DISCUSSION}

The main goal of this study was to compare two ways in which feedback was triggered (student- versus programme-assessed) and to evaluate the effect on learning effectiveness.

Although both treatments resulted in a significant learning effect, we found the programme-assessed CAI gave the best results overall, contrary to our expectations. It appeared that self-assessment as a way to trigger feedback did not have a beneficial effect because students, including those with both high and low levels of prior knowledge, were apparently very reluctant to choose the 'I don't know' option and thus hardly ever received elaborate feedback. Indeed, in the student-assessed CAI, students received elaborate feedback in an average of less than one in eight opportunities, although it should be stressed that they received minimal feedback in all other cases. In the programme-assessed treatment, in which the amount of feedback provided was based solely on the correctness of the answer, students received elaborate feedback in an average of four in eight opportunities. Thus, the student-assessed treatment in fact approached a 'minimal feedback only' condition, whereas the programme-assessed CAI turned out to be the really adaptive condition.

Any learning programme must not only offer learning opportunities, but must meet several conditions in order to ensure that effective learning takes place. ${ }^{11,12}$ Students should be able to recognise the learning opportunity as such, should be able to make use of it, and should be motivated to do so effectively. At the start of the experiment, the students in the student-assessed treatment were told that the CAI would adapt best to their prior knowledge if they used the 'I don't know' option appropriately. The 'I don't know' option was always clearly visible to the students on the opening screen. However, this

Table 4 Elaborate feedback and learning effectiveness as function of treatment and prior knowledge

\begin{tabular}{|c|c|c|c|c|c|c|c|c|}
\hline \multirow[b]{3}{*}{ Pre-test score } & \multicolumn{4}{|c|}{ Elaborate feedback } & \multicolumn{4}{|c|}{ Learning effectiveness } \\
\hline & \multicolumn{2}{|c|}{$\begin{array}{l}\text { Programme- } \\
\text { assessed }\end{array}$} & \multicolumn{2}{|c|}{ Student-assessed } & \multicolumn{2}{|c|}{$\begin{array}{l}\text { Programme- } \\
\text { assessed }\end{array}$} & \multicolumn{2}{|c|}{ Student-assessed } \\
\hline & Mean & SD & Mean & SD & Mean & SD & Mean & SD \\
\hline Low & 4.4 & 1.0 & 0.9 & 1.0 & 29.5 & 25.4 & 38.4 & 26.7 \\
\hline High & 3.3 & 1.7 & 0.5 & 0.7 & 38.9 & 42.9 & 1.0 & 52.5 \\
\hline
\end{tabular}


option was not explicitly presented as the way to access additional help (elaborate feedback) and thus may not have been recognised as a way to access more learning about the topic. Ironically, the 'I don't know' option was deliberately not presented as a 'get feedback here' option because we expected that the former option would provide better reassurance that it was acceptable to admit to not knowing the answer. It cannot be ascertained post hoc whether students did not use this option because they were convinced they knew the answer (misconception), or because they did not want to admit they needed help, or because they did not want to get help. Student motivation to make use of a learning opportunity is a complex condition influenced by both learnerrelated variables and the design and application of the instruction method. ${ }^{11,19}$ Although the learning activities in our experiment were clearly embedded in the genetics course and could in the long-term result in an improved final grade for this course, students might behave differently when points or credits could be earned immediately.

When we investigated the possible impact of prior knowledge on learning effectiveness, we observed that for students with a low level of prior knowledge, both CAIs were equally effective and resulted in a significant learning effect despite the difference between the treatments in the amount of feedback given. Thus, the mainly minimal feedback in the student-assessed treatment had a similar result to the mainly elaborate feedback in the programme-assessed treatment. A possible explanation for this is that the high amount of elaborate feedback in the programme-assessed treatment resulted in a cognitive overload, ${ }^{7,14}$ which can be related to the intrinsic conceptual difficulty of the subject.

Surprisingly, learning effectiveness in the studentassessed treatment was close to zero for students with a high level of prior knowledge, but was fairly high for students with a low level of prior knowledge.

Apparently, high prior knowledge was detrimental to the learning process in the student-assessed treatment, whereas this negative effect was not observed for low prior knowledge learners in this treatment or for either group in the programme-assessed treatment. It is possible that learners with high versus low levels of prior knowledge had different CAI experiences. The former may have perceived the CAI with mainly minimal feedback in the student-assessed treatment as a 'quiz' because, given their fairly extensive knowledge on the subject matter, they were more self-confident and were mainly interested in checking the correctness of their answers. They may have been less interested in the minimal feedback per se, which they may have scanned quickly. Post hoc, we noticed that high prior knowledge students indeed spent less time running through the CAI than others and more often indicated that they had not read the feedback completely. This may be related to the 'gaming the system' behaviour which has been repeatedly reported to occur in various interactive learning environments and to be associated with poorer learning. ${ }^{26,27}$ In the programmeassessed treatment, a wrong answer triggered elaborate feedback, which appeared as a new screen with additional questions and information and thus broke the monotony for high prior knowledge learners. We can presume that students with a low level of prior knowledge were generally less self-confident and as a result perceived the CAI as a more challenging learning experience and hence read the mainly minimal feedback in the student-assessed treatment more attentively. An alternative explanation for the lack of learning for high prior knowledge learners in the student-assessed treatment may relate to the presence of some strong misconceptions in the high prior knowledge learners. It has been shown that a conceptual change can only happen if the student encounters a plausible alternative theory, ${ }^{28}$ which would occur when elaborate feedback is presented, whereas minimal feedback will not be powerful enough to result in the rejection and remediation of misconceptions. Hence, in students with low prior knowledge the absence of any conceptions (and thus also the absence of misconceptions) may have been advantageous to the learning process.

The results shown here should not be extrapolated uncritically to other situations as the subject for which our CAIs were made is generally acknowledged to be intrinsically complex. In addition, the rather small sample size, the pre-test (making results only valid for pretested students), the use of similar questions in both pre- and post-tests, and the specific group of (Year 1) students should be taken into account when generalising these results. Presenting the post-test immediately after the CAI prevented contaminating factors from influencing post-test results; however, only the immediate and no long-term effects of the CAIs were measured.

We could not provoke the students into the behaviour needed to fully exploit the learning opportunities in this student-assessed CAI. Therefore, no firm conclusions about the potential benefits of student-invoked feedback can be formulated with this study. Further research is necessary; for example, it would be interesting to study the effect of adding an 
'I want help' option before or after the result of the answer is given.

The fact that the programme-assessed approach resulted in the highest level of learning effectiveness in our study corroborates the existing consensus that adapting the learning environment (in this case by providing either elaborate or minimal feedback) to the knowledge base level of the learner is worthwhile. In this respect, the positive effect of elaborate feedback on student appreciation is encouraging. Our discussion presents ways to further optimise feedback: for students with high prior knowledge, the prevailing misconceptions should be more explicitly handled, and for students with low prior knowledge, the complexity of the feedback should be minimised where possible to avoid cognitive overload. Achieving both goals at the same time requires that low and high prior knowledge learners are identified prior to the CAI and that both types of learner are subsequently provided with different kinds of elaborate feedback during the adaptive CAI.

Contributors: PE made substantial contributions to conception and design, acquisition of data, writing and revision of the manuscript. GvR made substantial contributions to the analysis and interpretation of the data, writing and revision of the manuscript. CvS made substantial contributions to conception and design and writing and revision of the manuscript. All authors approved the final version of the manuscript to be published.

Acknowledgements: Professor F Volckaert (KU Leuven, Leuven, Belgium) is thanked for allowing the experiment to be conducted during his course. Professor F Dochy (KU Leuven), Professor G Clarebout (KU Leuven) and Professor F Lombard (University of Geneva, Geneva, Switzerland) are acknowledged for their constructive remarks on earlier versions of the manuscript. Funding: none.

Conflicts of interest: none.

Ethical approval: not required.

\section{REFERENCES}

1 Brown CR. Some misconceptions in meiosis shown by students responding to an advanced level practical examination in biology. J Biol Educ 1990;24:182-6.

2 Kindfield ACH. Biology diagrams: tools to think with. J Learn Sci 1994;3 (1):1-36.

3 Roels P, Creten H, van Soom C. Value of adaptive computer-assisted instruction in teaching cell biology. J Med Educ 2009;43:491-2.
4 Dochy F, Segers M, Buehl MM. The relation between assessment practices and outcomes of studies: the case of research on prior knowledge. Rev Educ Res 1999;6:145-86.

5 Haertel GD, Walberg HJ, Weinstein T. Psychological models of educational performances: a theoretical synthesis of constructs. Rev Educ Res 1983;53:75-91.

6 Camp G, Paas F, Rikers R, van Merriënboer JJG. Dynamic problem selection in air traffic control training: a comparison between performance, mental effort, and mental efficiency. Comput Human Behav 2001;17:575-95.

7 Corbalán G, Kester L, van Merriënboer JJG. Selecting learning tasks: effects of adaptation and shared control on learning efficiency and task involvement. Contemp Educ Psychol 2008;33:733-56.

8 Kalyuga S. Expertise reversal effect and its implications for learner-tailored instruction. Educ Psychol Rev 2007;19:509-39.

9 Kalyuga S, Sweller J. Rapid dynamic assessment of expertise to improve the efficiency of adaptive e-learning. Educ Technol Res Dev 2005;53:83-93.

10 Salden RJCM, Paas F, Broers NJ, van Merriënboer JJG. Mental effort and performance as determinants for the dynamic selection of learning tasks in air traffic control training. Instr Sci 2004;32:153-72.

11 Clarebout G, Elen J. Benefits of inserting support devices in electronic learning environments. Comput Human Behav 2009;25:804-10.

12 Perkins DN. The fingertip effect: how informationprocessing technology shapes thinking. Educ Res 1985;14:11-7.

13 Chen C, Czerwinksi M, Macredie RD. Individual differences in virtual environments - introduction and overview. J Am Soc Inf Sci 2000;51:499-507.

14 Kelly D, Tangney B. Adapting to intelligence profile in an adaptive educational system. Interact Comput 2006;18:385-409.

15 Friend LC, Cole CL. Learner control in computerbased instruction: a current literature. Rev Educ Technol 1990;30:47-9.

16 Goforth D. Learner control = decision making + information: a model and meta-analysis. J Educ Comput Res 1994;11:1-26.

17 Large A. Hypertext instructional programs and learner control: a research review. Educ Inf 1996;14:95-108.

18 Williams MD. Learner-control and instructional technology. In: Jonassen DH, ed. Handbook of Research for Educational Communications and Technology. New York, NY: Macmillan Library 1996;957-83.

19 Clarebout G, Elen J. Tool use in computer-based learning environments: towards a research framework. Comput Human Behav 2006;22:389-411.

20 Winne PH. Why process product research cannot explain process product findings and a proposed remedy: the cognitive mediational paradigm. Teach Teach Educ 1987;3:333-57.

21 Elen J, Clarebout G. Supporting learners: increasing complexity? Comput Human Behav 2007;23:1162-6. 
22 Kruger J, Dunning D. Unskilled and unaware of it: how difficulties in recognising one's own incompetence lead to inflated self-assessments. J Pers Soc Psychol 1999;6:1121-34.

23 Pallant J. SPSS Survival Manual. A Step by Step Guide to Data Analysis using SPSS Version 12. Open University Press 2005. cfr. http://alexandriecsm.usj.edu.lb/ DocumentPrint.htm?numrec $=031051568923330$

24 Meltzer DE. The relationship between mathematics preparation and conceptual learning gains in physics: a possible 'hidden variable' in diagnostic pretest scores. Am J Phys 2002;70:1259-68.

25 Preacher KJ, Rucker DD, MacCallum RC, Nicewander WA. Use of the extreme groups approach: a critical re-examination and new recommendations. Psychol Methods 2005;10:178-92.
26 Baker RS, Corbett AT, Koedinger KR. Detecting student misuse of intelligent tutoring systems. Proceedings of the 7th International Conference on Intelligent Tutoring Systems. Comput Sci 2004;3220:531-40.

27 Baker RS, Walonoski J, Heffernan N, Roll I, Corbett A, Koedinger $\mathrm{K}$. Why students engage in 'gaming the system' behaviour in interactive learning environments. J Interact Learn Res 2008;19:185-224.

28 Chinn CA, Brewer WF. The role of anomalous data in knowledge acquisition: a theoretical framework and implications for science construction. Rev Educ Res 1993;63:1-49.

Received 17 December 2009; editorial comments to authors 18 March 2010; accepted for publication 1 July 2010 